\title{
CREATING VALUE THROUGH COMMUNICATION
}

\section{Estelle de Beer*}

Communication Management Division, University of Pretoria, South Africa

* Correspondence to: Private Bag X20, Hatfield, Pretoria 0028, South Africa. Tel.: +27 124205082.

E-mail address: estelle.debeer@up.ac.za

\section{ABSTRACT}

Communication can play a significant role in the value creation process of the organisation, considering the fact that the value of the capitals produced by the organisation can increase and decrease depending on what the organisation says and does. Integrating the corporate communication process into the strategic management, governance and value creation processes therefore pose an opportunity for communication professionals to illustrate how communication can contribute to the creation of value for organisations, and as such be of benefit to business and to society. Introducing these communication approaches to value creation in the organisation requires a new responsible, integrative perspective on the role of corporate communication.

\section{Keywords:}

Strategic communication

Value creation

Governance

Integrative communication perspective

Communication capital

\section{INTRODUCTION}

Over the past two decades the role of intangibles in creating value, has become increasingly important. Alan Greenspan, former Chairman of the Federal Reserve, stated in 2001: "Over time, and particularly during the last decade or two, an everincreasing share of GDP has reflected the value of ideas more than material substance or manual labour input" (Kalafut \& Low, 2001, p. 9). 
With an increasing recognition of the importance of intangible assets, there is also a need for a set of widely accepted metrics by which corporate leaders and the investment community can account for the non-financial factors that affect value creation in contemporary organisations. Although not always recognised as such, intangibles have always been a driver of corporate performance. Institutional investors are also increasingly taking intangibles into account in their analysis and earnings estimates. As a result, managers are more open to adopting non-traditional methodologies of measurement (Kalafut \& Low, 2000, p. 19). Recent management methods to measure intangibles include amongst others: the economic value added approach, the balanced scorecard and value-based management (Low, 2000, p. 253).

In order to address the co-creation of value from a holistic and organisational perspective, Roser, DeFillippi and Samson (2013, p. 22) refer to parallel streams rooted in the strategic alliance literature in management and the relational literature in marketing, which are now beginning to become conceptually intertwined. Leavy (2012, p. 15) furthermore refer to shareholder value and stakeholder value and quote Porter and Kramer when proposing that the purpose of the corporation must be redefined as creating "shared value", which involves "creating economic value in a way that also creates value for society".

Bygdås, Røyrvik and Gjerde (2004, p. 540) furthermore link intellectual capital and value creation and state that definitions about the former include the "knowledge and knowing capability of a social collectivity"; "knowledge that can be converted into value"; and Intellectual capital = competence + commitment. Although many perspectives can be found in the literature, Bygdås et al (2004, p. 540) state that intellectual capital can be divided into different categories such as human capital, structural capital and relational/customer capital due to the risk and ownership of the different components.

Against this background, communication competencies play an increasingly important role in an organisation's value creation process. Hamrefors (2010, p. 141) describes how communicators may contribute to the effectiveness of organisations by specifically participating in leadership. Findings of a study conducted by him 
indicate that communicators must develop certain knowledge and skills in order to contribute to organisational effectiveness. Four important areas of knowledge include: communication through processes, communication through structures, communication through social interaction; and communication to and from the environment. In addition, four areas of skills have also been identified and include: system design, mediating, coaching and influencing.

Malmelin (2007, p. 300) posits that an organisation's intangible assets refer to everything apart from its concrete material assets, which include its financial or physical assets. According to business theories, intangible assets refer to staff competencies, such as skills, knowledge and experience; the organisation's relations with stakeholders; management systems and databases of the organisation; and contracts and immaterial property rights such as trademarks. Malmelin (2007, p. 298) furthermore regards communication as an intangible organisational asset and developed a model that supports the closer integration of various dimensions of corporate communication in order to generate value in the marketplace.

Communication competencies and capabilities are hard to imitate and transfer, and its outputs and outcomes are more or less intangible. Identifying communication metrics that corporate leaders and others involved in shaping corporate performance can use to account for the contribution that communication makes to the value creation process, could assist communicators in illustrating their worth to organisations.

\section{VALUE CREATION}

Hamrefors (2010, p. 141) states that in addition to working with traditional communication activities, communicators must also build the communicative ability of the organisation in order to develop its total communicative effectiveness. The context in which communication is practised is also changing since the prerequisites for organisations to be able to act in the economic system is changing. Value creation traditionally took place in the value chain of which the logic is that several actors gradually refine a product or service in a simple chain structure. However, 
these value chains have over time become more complex and turned into value networks.

Skoog (2003, p. 487) also refers to the linear value creation phenomenon and posits that value creation over the past two centuries has been influenced by the industrial logic in which value is added in sequential stages in the process, based on the notion that each part can be optimised individually. In this way a contribution is made to overall organisational value creation. However, non-linear models of interpreting the creation and management of values in organisations are challenging traditional approaches.

New perspectives acknowledge stakeholders as co-producers of organisational value and stress the importance of co-inventing combinations and connectivity among the various actors. Skoog (2003, p. 488) argues that monetary expressions have to be put in constant relation to non-financial (intangible) organisational representations (eg different customer and employee relations and activities) in order to gain comprehensive meaning in both the short- and long-term organisational perspective. Organisational value creation is interpreted in the context of a perspective where personnel, customers and financial values are perceived as interdependent and equally important for the long-term survival of the organisation. In this way non-financial aspects of organisations are formally linked to financial ones in the value creation process.

Contemporary organisations are learning how to use the engagement experiences of stakeholders as the new basis for value creation in networks. Organisations interested in becoming co-creative for example, change the very nature of the relationship between management and employees, and between them and the cocreators of value, namely the stakeholders. For this, management needs to adopt a new mind-set and must initiate the evolution of a co-creative organisation (Ramaswamy, 2009, p. 32).

Establishing a co-creative organisation could impact its organisational structure. In this respect Walters (2004, p. 219) refers to the holonic or virtual organisational approach, which is: "[...] a set of companies that acts integratedly and organically; it 
is constantly re-configured to manage each business opportunity a customer presents. Each company in the network provides a different process capability and is called a holon."

In a holonic structure each business unit is equal to the others; the network is in dynamic equilibrium and it is self-regulating; information is open and flows across network boundaries; the network is evolutionary and is constantly interacting with its environment; and it is a knowledge-based, learning network (Walters, 2004, p. 220).

Eichentopf, Kleinaltenkamp and van Stiphout (2011, p. 650) posits that the past decade has brought a shift in how firms understand value creation. Interactive value creation or co-creation of value originated from service research as an attempt to differentiate services from products. From a marketing perspective, the level of customer participation was viewed as influencing the whole value creation process (Eichentopf et al, 2011, p. 651).

A study by Saarijärvi, Kannan and Kuusela (2013, p. 6) takes a broader perspective and concludes that the focus should be on identifying and understanding the kind of value that is co-created; for whom it is created; what resources are used; and through which mechanism it is created. Although a goods-dominant logic and/or manufacturing logic, as well as the old enterprise logic or product orientation are still prevailing, there is currently a shift towards a broader perspective on value creation.

Dobrzykowski, Tran and Tarafdar (2010, p. 106) furthermore distinguish between the resource based view (RBV) and value co-creation theories. RBV provides an internal view of the firm considering its core competencies, while value co-creation highlights the external perspective considering the role of customers in particular, or stakeholders in general, in value creation.

Saarijärvi et al. (2013, p. 7) argue that the focus should be on reinventing value in terms of the value-creating system itself where different actors or stakeholders work together to co-produce value. Customers would typically govern value creation in their own consumption context. They are not perceived as a passive target of marketing actions, but as active resources that can determine and create value. As 
such, they can reconfigure their roles from consumer, to contributor to creator. In this capacity they share the responsibility for the outcome, measured in terms of quality and added value. Value is created mutually and simultaneously by the organisation and by stakeholders, with both sides benefitting from co-operation. According to Prahalad and Ramswamy (2000, 2001) (in Saarijärvi, et al, 2013, p. 8) value becomes a joint function of the actions of the provider(s) and consumer(s) and is as such always co-created.

Lee, Olson and Trimi (2012, p. 817) present a macro view of the evolution of innovation for value creation, from the closed, to collaborative, to open and now coinnovation. They provide a conceptual overview of co-innovation through some of its basic elements such as convergence revolution, collaboration and co-creation with stakeholders. Their approach suggests that co-innovation is a new innovation paradigm where new ideas from various internal and external sources are integrated to generate new organisational and shared values. Since co-innovation involves engagement, co-creation and experience for value creation, the practices of coinnovative organisations are difficult to imitate by competition and are therefore strategically relevant. These approaches not only create value for organisations, but they also create shared value for all stakeholders.

Roser et al (2013, pp. 20-22) also use co-creation theory to integrate insights from management and marketing literatures that are concerned with co-creation phenomena. They define co-creation as "an interactive, creative and social process between stakeholders that is initiated by the firm at different stages of the value creation process". Instead of a transactional approach and the value or utility embedded in goods, the new logic focuses on the co-creation of values and relationships and suggests a collaboration-focused view of customer and stakeholder relations. Value creation increasingly takes place in networks and becomes less dependent on an organisation's value proposition alone.

The associated brand logic involves dynamic and social processes, in which all stakeholders are considered. From this perspective, brand value is not only cocreated through dyadic relationships between firms and individual customers, but is also co-created through network relationships and social interactions among 
stakeholders. Roser et al (2013, pp. 20-22) conclude by stating that implementation decisions in one dimension of co-creative design (eg whom to involve in co-creation) will affect other dimensions of implementation and governance (eg how much intimacy) and thus how co-creation needs to be managed. The benefits of cocreating value also include better product quality, greater customer satisfaction and reduced risk.

The International Integrated Reporting Council's (IIRC) Consultation Draft of the International $<\mid R>$ Framework (2013, p. 16) states that an organisation can create value by serving the interest of, and working with all its stakeholders. Value created in this way manifests in financial returns for providers of financial capital. It also has positive or negative effects on capitals, which are stores of value, created for an organisation and its stakeholders as a result of its increase, decrease or transformation caused by the organisation's activities and outputs. Financial returns are dependent on inter-relationships between various types of capital. In addition, value is determined by a wide range of interactions, activities, relationships, causes and effects. Value is also created over different time horisons and for different stakeholders through different capitals.

Value drivers furthermore affect an organisation's ability to create value over time. These capabilities provide competitive advantage; an organisation has some degree of control over it; and their type and combination will differ in different organisations. Value drivers identified by the Consultation Draft of the International $<\mid R>$ Framework (2013, p. 16) include: financial drivers (growth in sales and market share, pricing, strategy, operational efficiency, brand equity, and the cost of financial capital); customer relations (responses to societal expectations and environmental concerns, innovation and corporate governance); and values (such as integrity, trust and teamwork).

The value creation index of The Cap Gemini Ernst \& Young Center for Business Innovation $(\mathrm{CBI})$ identified the following value drivers as part of a set of value creation metrics that it has developed: innovation; quality; customer relations; management capabilities; alliances; technology; brand value; employee relations; and environmental and community issues (Kalafut \& Low, 2001, p. 10). With this set 
of standardised measures, weighted according to their relative impact, managers have the tools to better drive and monitor their company's future performance. Investors are also equipped with a more robust and uniform way of evaluating companies (Low, 2000, p. 253).

\section{THE CAPITALS}

Literature on value creation refers to numerous kinds of capitals. For the purpose of this paper, the following capitals mentioned in the Consultation Draft of the International $<\mathrm{IR}>$ Framework (2013, p. 12) are relevant:

- Financial capital: Refers to the pool of funds that, amongst others, is available to an organisation for use in the production of goods or the provision of services.

- Manufactured capital: Manufactured objects that are available for the production of goods or the provision of services.

- Intellectual capital: Refers to organisational, knowledge-based intangibles, including intellectual property (patents, copyrights, software, rights and licences); "organisational capital" (tacit knowledge, systems, procedures and protocols); and intangibles (associated with the brand and corporate reputation).

- Human capital: Refers to people's competencies, capabilities and experience, and their motivations to innovate.

- Social and relational capital: Specifically relevant to the communication profession. Refers to the institutions and the relationships within and between communities, groups of stakeholders and other networks; and to the ability to share information to enhance individual and collective well-being. Includes: shared norms, and common values and behaviours; key stakeholder relationships, and the trust and willingness to engage with external stakeholders; and an organisation's social licence to operate.

- Natural capital: Refers to renewable and non-renewable environmental resources and processes that provide goods or services and that support the past, current or future prosperity of an organisation. 
In this context the International $<\mid R>$ Framework (2013, p. 13) states that the extent to which organisations, collectively or individually, are building up or running down the various capitals can have an important effect on the availability, quality and affordability of these capitals, particularly because they are in limited supply and are non-renewable. This can affect the organisation's ability to create value over time.

Two kinds of capital that are of particular importance to communication practitioners are: intellectual capital, and social and relational capital. O'Donnell, O'Regan and Coates (2000, p. 187) theorise intellectual capital creation as a dynamic process of collective knowing that is capable of being leveraged into market value. They propose that interaction, as distinct from individual action, becomes the basic unit of theoretical analysis. The argument is based on the set of symmetrical and reciprocal relations presupposed in Habermas' theory of communicative action. The benefit of the medium of communicative action, viewed by the authors as the nexus of intellectual capital creation, is that it consists of substantive and real phenomena, which are open to empirical investigation.

From this perspective human interaction is the critical source of intangible value in the intellectual age, that represent an increasingly knowing-intensive economy. O'Donnell, O'Regan, Coates, Kennedy, Keary and Berkery (2003, p. 82) argue that human interaction should be placed at the center of an enlightened economic and social equation. O'Donnell (2004, p. 294) continues the debate by presenting some theoretical insights into how intellectual capital is created linguistically in social space. He specifically refers to the "process" of intellectual capital creation.

Tomé (2008, p. 499) also refers to the social dimension of the phenomenon of intellectual capital and states that the latter is possessed by individuals, companies, organisations, regions and countries. From a social perspective intellectual capital can be regarded as the sum of various phenomena: education, training, work experience, know-how, science, technology, patents, organisational routines and social relations.

In the context of the capitals, Smedlund (2008, p. 63) defines social capital as a network of individuals with shared norms, beliefs and trust. Social capital, especially 
trust-based-ties, develops in interaction processes, accelerates knowledge flow, and acts as an informal governance mechanism between firms. Mu, Peng and Love (2008:86) assert that the process through which social capital facilitates knowledge flow and innovation enhances the understanding of a firm's strategic behaviour. It also provides managers with possible guidelines on how to accumulate social capital in interfirm interaction to gain competitive advantage.

Alguezaui and Filieri (2010, p. 891) also posit that social capital is considered to be the facilitator of knowledge search and knowledge sharing activities, which are important to innovation outcomes. McCullum and O'Connell (2009, p. 152) furthermore clarify the role that human capital or social capital capabilities play in present and future leadership. They state that as organisations face volatile and virtual environments there is a growing need to equip emerging leaders with skills to generate, utilise and maintain social capital. Social capital skills development could include adopting an open-systems organic mind-set, leveraging relational aspects of leadership development and building networking and story-telling skills.

In a study by Fussell, Harrison-Rexrode, Kennan and Hazleton (2006, p. 148), the connection between social capital, transaction costs and organisational outcomes is investigated. They refer to three dimensions of social capital, namely structure, relationships and communication; transaction cost (information exchange, problem solving, conflict management and behaviour regulation); and organisational outcomes (quality, change, equity and fairness). Kelley's personal relationship theory can be used to explain the maintenance and success of alliance outcomes and can include communication between supply chain partners as a major component of relational capital in addition to trust and commitment. Strategic alliance outcomes are regarded as being: goal, value-creation and re-evaluation oriented (Sambasivan, Siew-Phaik, Mohamed \& Leong, 2011, p. 548).

Corporate reputation also plays a role in developing relational capital from the perspective of the resource based view. De Castro, Sáez and López (2004, p. 575) argue that corporate reputation is considered as a triggering and moderating element for interorganisational relations, which could lead to organisational outcome 
improvement. They also suggest that relational capital be included within the concept of "social capital".

Malmelin (2007, p. 298) furthermore refers to communication capital in his development of a new model, which addresses the current challenges of corporate communication within the framework of intellectual capital research. $\mathrm{He}$ conceptualises communication capital as consisting of juridical capital, organisational capital, human capital and relational capital. The proposed model emphasises the closer integration of organisational communication with business operations and strategies. His ideas are applicable to the management, development and planning of communication in different kinds of organisations.

\section{FROM A COMMUNICATION LOGIC TO A COMMUNICATIVE LOGIC}

According to Malmelin (2007, p. 298) communication competence is set to become a critical success factor for business, which requires a broad understanding of communication. The narrow understanding of corporate communication in terms of press releases and media relations will have to make way for a broader view of a function that cuts through and involves the whole organisation. One that comprises both internal communication within the organisation and communication with stakeholders and publics outside the organisation.

Massie and Anderson (2003, p. 223) argue that it has become imperative for organisations to communicate effectively because of the intense and competitive nature of business in contemporary society. As such, communication is a fundamental part of managing. From a communication perspective, Van Riel (1992) (in Massie \& Andersen, 2003, p. 223) distinguishes between three main forms of communication, namely: management communication, marketing communication and organisational communication. Building on the different kinds of communication, the communication strategy should determine the role for communication mechanisms and implications for operations in product performance, distribution methods, product pricing and staff training. 
From the above it is clear that the communication logic is important to realise the goals and objectives of organisations. However, Hamrefors (2010, p. 150) states that: "As society is turning into a market of value networks, communication functions can no longer stay in their restricted domains and only deal with traditional communication issues. They still of course, must be proficient with the tools of the trade, but must also develop so that they can take responsibility for building the communicative abilities of their organisations." "....to be chosen as a contributor to leadership requires, in addition, that the communicator is able to influence everything that builds the communicative ability of the organisation. This is the role of contextual leadership."

Hamrefors (2010, p. 143) argues that whereas ideological leadership develops and communicates the conceptual platform of the organisation, contextual leadership must develop the organisation's relationships to all parties relevant to the network. This kind of leadership must develop the organisation's ability to foresee coming events in the environment and create balanced relationships with many different categories of actors.

Understanding how people function cognitively in their perceptions and in perspective making is important in a leadership role. Hamrefors (2010, p. 143) regards the understanding of the mechanisms of human perception as a basic competence of a communicator. He concludes his research by stating that the purpose of communication is to establish and develop the communicative ability of the whole organisation rather than to deal only with traditional communication activities. Communicative ability strengthens the conceptual foundation of the organisation and stimulates a variety of activities.

O'Donnell, O'Regan and Coates (2000, p. 188) regard the communicative relation between people as the "nexus of intellectual capital creation". As such, intellectual capital is viewed as dynamic rather than static, and as a collectivist as distinct from an individualist perspective. From a pragmatic perspective this is a talking, communicating, thinking, feeling and doing process of ongoing activity that is embedded within specific communities of practice. 
O'Donnell (2004, p. 296) furthermore argues that our discourses create social realities in the intellectual capital field and refers to a "linguistic turn" away from individual action to interaction and a focus on the communicative relation between people through speech and argumentation theory. He also regards Habermas' elaboration of the process of human interaction and dialogue as manifest in the communicative relation, and not in the individual action, as one of the most sophisticated approaches in social theory.

Kernstock and Brexendorf (2009, p. 389) used Habermas' "theory of communicative action" (TCA) to include interaction in the field of corporate brand management. This approach has implications for stakeholder interactions within this field. With the rise of corporate marketing the concept of corporate brand management shifted from an intrapersonal based view of brand management to a more interpersonal approach to understanding the brand. From this perspective a corporate brand develops its meaning and its performance by influencing the entire corporate sphere of stakeholders. Habermas's theory of communicative action reflects the interactions between the stakeholders of the corporate brand. Kernstock and Brexendorf (2009, p. 391) also refer to stakeholder management within strategic management. Whereas strategic management and stakeholder management take a top-down perspective on corporate activities, corporate marketing culminates from the bottomup, relating to different marketing, branding and communication concepts.

Rose-Anderssen, Baldwin and Ridgeway (2010, p. 193) refer to communicative interaction as an instrument for integration and co-ordination. Practices of integration and co-ordination through communicative interaction are emerging while producing innovative solutions and competitive advantage. They argue from their research that the multi-voiced interaction between partners in the supply chain assists for example in moving the product beyond what the manufacturer could have created alone. In this case communicative interaction within the supply chain is used for co-construction of meaning to enhance change and development.

They furthermore explored the effects of communicative interaction on meaning construction and demonstrated that a collective approach of multi-voices enhances 
the potential for expanding on the meaning that can be created by one individual alone (Rose-Anderssen, Baldwin \& Ridgeway, 2010, p. 196).

\section{FROM INTEGRATED COMMUNICATION TO INTEGRATIVE COMMUNICATION}

According to Christensen, Firat and Cornelissen (2009, p. 207) integration in communication is beyond reach, "at least if the full process of communication is taken into proper consideration". They regard the most powerful driver behind integration to be a combination of inquisitive publics and critical media and journalists. Integrated communication no longer refers exclusively to the coordination of corporate design or strategic alignment of marketing parameters, but also involves the pursuit of a coherent and shared corporate culture or shared values; the vertical integration of partners, customers and non-governmental organisations; and the maintenance of positive relations with politicians, journalists and the media.

The logical consequence is that the field of integrated communication is expanding from a bounded and specialised activity to an organisation-wide issue and concern, which spans functional and disciplinary boundaries. It is no longer a set of tactical activities, but an ongoing strategic process that considers the issues of identity and legitimacy and, ultimately, organisational survival (Christensen, Firat \& Cornelissen, 2009, p. 210).

Malmelin and Hakala (2009, p. 248) furthermore posit that integration has been approached and considered primarily from a marketing perspective, which is why it has not developed into an all-embracing concept that governs communications throughout the organization. The responsibility for integrated communication should be at the top of the organisational pyramid where all communication efforts can converge around a clear and distinct set of messages and symbols. According to Christensen, Firat and Cornelissen (2009, pp. 210, 215) "the combination of social expectations, message expansion, blurred disciplinary boundaries, and managerial involvement implies a growing pressure on organisations to integrate their communications on a broader scale than was the case in the past". They state that 
organisational leaders also increasingly seek to master communication as a general managerial competence.

Johansen and Andersen (2012, p. 272) build on this argument and propose a reconceptualisation of the concept from an intra-organisational perspective towards a co-creation perspective. They suggest a relocation of the discussion of integration from a corporately controlled, intra-organisational endeavour to a societal-constituent perspective. The societal-constituent perspective focuses on "empowered, engaged, culturally adept social actors who present to corporations a range of conflicting societal and economic interests". Market voices are invited to merge into corporate space taking co-ownership in negotiating corporate and individual identities. These involvement strategies corresponds with new emerging market concepts and the notion of value creation where the roles of companies and customers in particular, and stakeholders in general, have converged in the process of value creation. Value is not created for customers and other stakeholders, but rather with them. According to Prahalad and Ramaswamy (2004:5) (in Johansen \& Andersen, 2012, p. 283) "the interaction between the firm and the consumer is becoming the locus of value and value extraction".

It is argued in this paper that integrative thinking should precede co-creation in the value creation process. Value creation typically takes place in complex contexts "where there is no clear right or wrong decision and where the choices are not either or" (Martin, 2007) (in Benson \& Dresdow, 2009, p. 510). These situations require thinking about two or more conflicting ideas in constructive tension - a process typically called integrative thinking.

Benson and Dresdow (2009, p. 508) describes this ability of integrative thinking as the ability to integrate diverse facts, ideas, issues and connections into more comprehensive integrative thinking for decision-making. "Interdisciplinary thinking, engagement, flexibility, individual customization, collaboration and inspiration are critical factors for the development of creative and integrative thinking skills for managers." In an effort to develop an integrative management model for intellectual capital, Litschka, Markom and Schunder's (2006, p. 106) also emphasised the importance of integrative thinking in value creation. 
Karakas and Kavas (2008, p. 8) defines the term integrative thinking as:

"... the ability to constructively reconcile the tensions of opposing models, and instead of choosing one model at the expense of the other, generating a creative resolution and a holistic model that contains elements of the individual models, but goes beyond them. The integrative thinking model is based on four steps: salience, causality, architecture, and resolution".

One of the core principles of value creation in the context of integrated reporting is also that of integrated thinking. The Consultation Draft of the International $<\mid R>$ Framework (2013, p. 8) refers to integrated thinking as:

"...the active consideration by an organisation of the relationship between its various operating and functional units and the capitals that the organisation uses and affects. Integrated thinking leads to integrated decision-making and actions that consider the creation of value over the short, medium and long term".

\section{VALUE CREATION: A NEW PERSPECTIVE ON CORPORATE COMMUNICATION}

Malmelin (2010, p. 300) argues that a key resource for future business will be communication, since business success depends increasingly on an organisation's communication and its effectiveness. A greater part of differentiation and value creation takes place through communication by means of images, conceptions, stories and experiences.

However, the research tradition of corporate communication lacks descriptive models that seek to integrate various dimensions of corporate communication as a corporate resource. Communication capital is understood as an asset and resource for the whole organisation, and includes internal and external communication. It also comprises communication systems, communication competencies and relations inside and outside the organisation. Viewed as a form of intellectual capital, communication can be understood as an integral part of the management of an organisation, the tasks of which include building and increasing the organisation's intangible assets (Malmelin, 2010, p. 301). 
Communication should also be regarded as an organisation-wide activity managed by communication professionals. Forms of intellectual capital, such as relations, networks, competencies and trust require strong communication skills of staff, while the organisation itself must have appropriate communication structures that promote openness and dialogue. The management of an organisation's communication capital requires an in-depth analysis of what communication as an organisational asset consists of. Malmelin (2010, p. 301) argues that the role of communication professionals in modern organisations is shifting in an analytical and strategic direction, in support of what Hamrefors (2010) suggests on the topic of communicative leadership.

Malmelin and Hakala (2009, p. 248) propose "integrative brand management", from an integrative corporate communication perspective, as a solution to the challenge faced by communication professionals to integrate communications. Their frame offers a way of thinking that integrates different divisions and specialists in the organisation, while simultaneously addressing the organisation's business and communication goals. From this perspective they stress the co-operation between different units, departments and schools of thought.

Integrative brand management involves the whole organisation in communicating and building the brand and is divided into the following three dimensions: organisation guided by the brand; communications guided by the brand; and reputation guided by the brand (Malmelin \& Hakala, 2009, p. 249).

In this context, organisations need to broaden their perspective on integration from an intra-organisational to a more holistic, integrative approach, initiating processes of organisational integration that merge stakeholders' voices into the development of corporate strategy. Implications involve the organisation's ability to listen to, selfreflect and co-develop with stakeholders as part of a responsible integrative approach to strategic communication management (Johansen \& Andersen, 2012, p. 284). 
The King Report on Corporate Governance for South Africa (2009, p. 13) refers to the stakeholder inclusive approach to governance in addressing the same phenomenon of considering the legitimate interest and expectations of stakeholders other than shareholders. The board of directors considers these expectations in their strategic decision making on the basis that it is in the best interest of the company, as a sustainable enterprise and responsible corporate citizen, to do so.

As such, the value chain is extended and integrated into a wider triple context (people, planet and profit) environment, providing a holistic perspective for brand equity. According to Johansen and Andersen (2012, p. 284): "Co-creation is not limited to include external stakeholder dialogue, but is premised upon a reconceptualisation of the organisation's internal value chain as an integrated part of larger value co-created networks".

The new demands for companies wishing to engage in the practice of stakeholder value creation, include: dialogue, access, transparency and understanding of riskbenefits. Dialogue and interaction are central in this context (Johansen \& Andersen, 2012, p. 283).

Walters, Halliday and Glaser (2002, p. 775) refer to a new business model that is emerging, in which competitive advantage is based upon managing processes that facilitate responses to "market" change and where new capabilities are based upon developing unique relationships with partners. Relationship management, knowledge management and technology management are three disciplines that, together with the current view of business organisations, are process management oriented, rather than organised around traditional functions, in the breaking down of barriers between functions.

From this interactive perspective relationship management can influence the positioning and strategy of the organisation by identifying, developing and maintaining relationships which ensure that amongst others, product service objectives and customer expectations are met. Relationship management also extends the scope of relationship marketing into one in which a broad range of processes can be co-ordinated (Walters, Halliday \& Glaser, 2002, p. 775). 
The International $<\mid R>$ Framework states that value is not created by or within an organisation alone, but is created through relationships with others. Stakeholders provide insights about issues that are important to them and that also affect the organisation, including economic, environmental and social issues. Two aspects that are relevant in building trust and resilience are:

- The nature and quality of the organisation's relationship with key stakeholders

- How key stakeholders' legitimate needs, interests and expectations are understood, taken into account and responded to.

If integrated thinking is embedded in the business, a fuller consideration of stakeholders' legitimate needs, interests and expectations is incorporated as an ordinary part of conducting business.

The Framework (2003, p. 18) furthermore asserts that the organisation may accept stewardship responsibilities in accordance with growing stakeholder expectations to do so. Responding to stakeholders' legitimate needs, interests and expectations in this way is consistent with the concept of value and value creation.

\section{CONCLUSION}

The next challenge for communication professionals will be the development of communication metrics that could illustrate the value that communication creates for business and for society in a triple context environment. Including Hamrefors' (2010) suggested areas of knowledge, namely communication through processes, communication through structures, communication through social interaction and communication to and from the environment; and including the skills of system design, mediating, coaching and influencing, into a value creation metric for communication could solidify the communication professional's position on top management level in the organisation.

Other studies that could provide input to the development of such a metric of communication competencies include the Annenberg Strategic Communication and 
Public Relations Centre's (University of Southern California) biennial Communication and Public Relations Generally Accepted Practices Study, co-ordinated by Jerry Swerling; as well as the annual European Communication Monitor, co-ordinated by Ansgar Zerfass from the University of Leipzig.

Since non-financial performance accounts for as much as 35 percent of institutional investors' valuation of a company, managing the internal and external communication processes in a responsible, integrative manner has become imperative in the creation of value in the perceptual arena of the organisation. Demonstrating that communication can be regarded as the nexus of value creation could ensure sustainable long-term support for the function and the relevant communication processes.

\section{LIST OF REFERENCES}

Alguezaui, S. \& Filieri, R. (2010). Investigating the role of social capital in innovation: sparse versus dense network. Journal of Knowledge Management, 14(6), 891-909

Benson, J. \& Dresdow, S. (2009). Common sense and integrative thinking. Management Decision, 47(3), 508-517.

Bygdås, A.L., Røyrvik, E. \& Gjerde, B. (2004). Integrative visualisation and knowledge-enabled value creation: An activity-based approach to intellectual capital. Journal of Intellectual Capital, 5(4), 540-555.

Christensen, L.T., Firat, A.F. \& Cornelissen, J. (2009). New tensions and challenges in integrated communications. Corporate Communications: An International Journal, 14(2), 207-219.

De Castro, G.M., Sáez, P.L. \& López, J.E.N. (2004). The role of corporate reputation in developing relational capital. Journal of Intellectual Capital, 5(4), 575-585. 
Dobrzykowski, D.D., Tran, O. \& Tarafdar, M. (2010). Value co-creation and resource based perspectives for strategic sourcing. Strategic Outsourcing: An International Journal, 3(2), 106-127.

Eichentopf, T., Kleinaltenkamp, M. \& van Stiphout, J. (2011). Modelling customer process activities in interactive value creation. Journal of Service Management, 22(5), 650-663.

Fussell, H., Harrison-Rexrode, J., Kennan, W.R. \& Hazleton, V. (2006). The relationship between social capital, transaction costs and organisational outcomes: $A$ case study. Corporate Communication: An International Journal, 11(2), 148-161.

Hamrefors, S. (2010). Communicative leadership. Journal of Communication Management, 14(2), 141-152.

Institute of Directors (IoD) (2009). King Report on Governance for South Africa, 2009 (King III Report), Institute of Directors, Johannesburg

International Integrated Reporting Council (IIRC) (2013). Consultation Draft of the International $<I R>$ Framework. April 2013.

Johansen, T.S. \& Andersen, S.E. (2012). Co-creating ONE: rethinking integration within communication. Corporate Communications: An International Journal, 17(3), 272-288.

Kalafut, P.C. \& Low, J. (2001). The value creation index: quantifying intangible value. Strategy \& Leadership, 29(5), 9-15.

Karakas, F. \& Kavas, M. (2008). Creative brainstorming and integrative thinking: skills for $21^{\text {st }}$ century managers. Development and Learning in Organizations, 22(2), 8-11. 
Kernstock, J. \& Brexendorf, T.O. (2009). Implications of Habermas's "theory of communicative action" for corporate brand management. Corporate Communication: An International Journal, 14(4), 389-403.

Leavy, B. (2012). Getting back to what matters - creating long-term economic and social value. Strategy \& Leadership, 40(4), 12-20.

Lee, S.M., Olson, D.L. \& Trimi, S. (2012). Co-innovation: convergenomics, collaboration, and co-creation for organisational values. Management Decision, 50(5), 817-831.

Litschka, M., Markom, A. \& Schunder, S. (2006). Measuring and analysing intellectual assets: an integrative approach. Journal of Intellectual Capital, 7(2), 160173.

Low, J. (2000). The value creation index. Journal of Intellectual Capital, 1(3), 252262.

Malmelin, N. (2007). Communication capital: Modelling corporate communication as an organisational asset. Corporate communication: An International Journal, 12(3), 298-310.

Malmelin, N. \& Hakala, J (2009). Guided by the brand: from brand management to integrative corporate communication. Business Strategy Series, 10(5), 248-258.

Massie, L. \& Anderson, C.L. (2003). Integrating communications: is the ideal achievable? Corporate Communications: An International Journal, 8(4), 223-228.

McCallum, S. \& O'Connell, D. (2009). Social capital and leadership development: Building stronger leadership through enhanced relational skills. Leadership \& Organisational Development Journal, 30(2), 152-166.

Mu, J., Peng, G, \& Love, E. (2008). Interfirm networks, social capital and knowledge flow. Journal of Knowledge Management, 12(4), 86-100. 
O'Donnell, D., O'Regan, P. and Coates, B. (2000). Intellectual capital: a Habermasian introduction. Journal of Intellectual Capital, 1(2), 187-200.

O'Donnell, D., O'Regan, P., Coates, B., Kennedy, T., Keary, B. \& Berkery, G. (2003). Human interaction: the critical source of intangible value. Journal of Intellectual Capital, 4(1), 82-99.

O'Donnell, D. (2004). Theory and method on intellectual capital creation: Addressing communicative action through relative methodics. Journal of Intellectual Capital, 5(2), 294-311.

Ramaswamy, V. (2009). Leading the transformation to co-creation of value. Strategy \& Leadership, 37(2), 32-37.

Roser, T., DeFillippi, R. \& Samson, A. (2013). Managing your co-creation mix: cocreation ventures in distinctive contexts. European Business Review, 25(1), 20-41.

Rose-Anderssen, C., Baldwin, J. and Ridgeway, K. (2010). Communicative interaction as an instrument for integration and coordination in an aerospace supply chain. Journal of Management Development, 29(3), 193-209.

Saarijärvi, H., Kannan, P.K., \& Kuusela, H. (2013). Value co-creation: theoretical approaches and practical implications. European Business Review, 25(1), 6-19.

Sambasivan, M., Siew-Phaik, L., Mohamed, Z.A. \& Leong, Y.C. (2011). Impact of interdependence between supply chain partners on strategic alliance outcomes. Management Decision, 49(4), 548-569.

Skoog, M. (2003). Visualising value creation through the management control of intangibles. Journal of Intellectual Capital, 4(4), 487-504.

Smedlund, A. (2008). The knowledge system of a firm: social capital for explicit, tacit and potential knowledge. Journal of Knowledge Management, 12(1), 63-77. 
Tomé, E. (2004). Intellectual capital, social policy, economic development and the world evolution. Journal of Intellectual Capital, 5(4), 648-665.

Tomé, E. (2008). The hidden face of intellectual capital: social policies. Journal of Intellectual Capital, 9(3), 499-518.

Walters, D. Halliday, M. \& Glaser, S. (2002). Creating value in the "new economy". Management Decision, 40(8), 775-781.

Walters, D. (2004). New economy - new business models - new approaches. International Journal of Physical Distribution \& Logistics Management, 34(3/4), 219229. (Consultation Draft of the International $<I R>$ Framework 2013:16). 